\title{
Parasitose intestinal humana: estudo narrativo acerca das publicações científicas
}

A parasitose intestinal é acometida por microrganismos infecciosos que estão intrinsicamente relacionados a condições de precariedade sanitária, condições de moradias e em alguns casos ausência de informação quanto à higiene, tornando-se assim grande problemática de saúde púbica de repercussão mundial inclusive no Brasil com números considerados elevados de mortalidade. A OMS divulgou no ano de 2000 que em média 3,5 bilhões de pessoas foram acometidos, dentre elas mais de 450 milhões eram crianças. Assim surge a inquietação frente como tem se dado estudos científicos epidemiológicos das parasitoses intestinais humana publicados a partir deste ano 2000 no Brasil, bem como levantar estudos frente a identificações dos parasitas que possui tropismo Intestinal sua etiologia, morfologia e sinais e sintomas da doença. Além disso, contribuir e cooperar para conhecimento desta problemática permeando um direcionamento para planejamentos, profilaxia, educação em saúde a partir dos estudos existentes. Este estudo se efetiva a partir de revisão bibliográfica de cunho qualitativo narrativo de artigos científicos completos dispostos no Google Acadêmico e SiELO com buscas a partir dos descritores: Perfil Epidemiológico; Parasitologia e Parasitose Intestinal Humana e Livros que retratem essa temática. Do qual não fora encontrado trabalhos com datas recentes. Este estudo se encontra organizado em II capítulos, sendo abordado no I - Resumo, Introdução e Perfil Epidemiológico; II- Epistemologia do Estudo da Parasitose no Brasil e por fim III- Discrição das Parasitoses Intestinal Humana e Considerações Finais. Logo, foi possível contatar que mesmo com grande incidência de casos acometidos ainda a precariedade de publiçações de artigos científicos que permeiam esta temática no Brasil, no entanto há existência de materiais tais como livros de autores renomados e manuais disposto pelo ministério da saúde que descreve com excelência os conceitos, parasitas sinais e sintomas das doenças parasitarias intestinal conforme pode ser descrito neste trabalho.

Palavras-chave: Epidemiologia; Parasitose Intestinal; Humana.

\section{Human intestinal parasitosis: narrative study about scientific publications}

Intestinal parasittosis is caused by infectious microorganisms that are intrinsically related to precarious sanitary conditions, housing conditions and in some case lack of hygiene information, thus becoming a major public health problem with a worldwide repercussion, including in Brazil with numbers considered mortality The WHO reported in 2000 that on average 3.5 million people were affected, of which more than 450 billion were children. Thus arises the restlessness as has been given epidemiological scientific studies of human intestinal parasitoses, published since this year 2000 in Brazil, as well as raise studies on the identification of parasites that has intestinal tropism its etiology, morphology and signs and symptoms of the disease. In addition, to contribute and cooperate to know this problematic permeating a direction for planning, prophylaxis, health education from the existing studies. This study is effective from a bibliographic review of a qualitative narrative of complete scientific articles arranged in Google Scholar and siELO with searches from the descriptors: Epidemiological Profile; Parasitology and Human Intestinal Parasitosis and Books that portray this theme. This study is organized in III chapters, being addressed in I - Abstract, Introduction and Epidemiological Profile; II - Epistemology of the Study of Parasitosis in Brazil and finally III - Discretion of Human Intestinal Parasitoses and Final Considerations. Therefore, it was possible to contact that even with a high incidence of cases still affected by the precariousness of publications of scientific articles that permeate this subject in Brazil, nevertheless there is existence of materials such as books of renowned authors and manuals arranged by the ministry of health that describes with excellence concepts, parasite signs and symptoms of parasitic intestinal diseases as can be described in this paper.

Keywords: Epidemiology; Intestinal Parasitosis; Human.

Topic: Parasitologia

Reviewed anonymously in the process of blind peer.
Received: 05/06/2020

Approved: $14 / 08 / 2020$
Jéferson Pereira da Silva (it)

Instituto Federal de Mato Grosso, Brasil http://lattes.cnpq.br/9857846961124620 http://orcid.org/0000-0002-5056-2023 jefersonjuniorpereira@hotmail.com

\section{Referencing this:}

SILVA, J. P.. Parasitose intestinal humana: estudo narrativo acerca das publicações científicas. Scire Salutis, v.10, n.3, p.1-11, 2020. DOI: http://doi.org/10.6008/CBPC2236-9600.2020.003.0001 


\section{INTRODUÇÃO}

As contaminações e infecções por microrganismos principalmente por parasitas intestinais tem sido uma grande problemática no quesito de saúde pública não só no contexto do Brasil, mas mundial. Estas estão sempre atreladas à precariedade do saneamento básico e condições de moradia e até mesmo por falta de informação. Visto que, o seu agravamento pode ocasionar quadros de anemia, desnutrição e morte.

Assim, a discussão destes agentes é de extrema relevância para os gestores, comunidade, estudantes e para os profissionais que atuam na área da saúde, devido ao grande número de áreas geográficas que encontram em situações de precariedade no país. Pois, a parasitose intestinal está inteiramente elencada aos elevados índices de mortalidade no mundo. De acordo com a Organização Mundial da Saúde no ano de 2000, o número de infectados no mundo está estimado em aproximadamente 3,5 bilhões de pessoas, sendo das quais 450 milhões são crianças doentes.

Nesta perspectiva esta pesquisa permeia à solução da seguinte problemática: Como tem se dado os estudos epidemiológicos das parasitoses intestinais no Brasil?. Isso mediante a identificação de quais parasitas intestinais é mais evidente nos estudos, contribuindo para um delineamento do perfil epidemiológico, conhecimento frente à etiologia, morfologia, reprodução e os sinais e sintomas ocasionados pela contaminação. Assim como, cooperar significativamente para o conhecimento desta problemática, permitindo um direcionando para um planejamento, profilaxia e educação em saúde além do apuramento e fortalecimento referente à produção científica neste viés.

Neste contexto, o presente estudo visa realizar um levantamento a partir das publicações cientificas para construção do analise do perfil epidemiológico das Parasitoses Intestinais Humanas, a fim de demostrar como tem desencadeado as pesquisas e trabalhos nesta perspectiva, bem como qual incidência destes microrganismos nos estudos já realizados, contribuindo significativamente para um planejamento e investigação em saúde.

Neste aspecto o respectivo estudo está organizado em 3 capítulos sendo que no I - Será apresentado o Resumo, Introdução, que remete uma visão geral do trabalho e a revisão teórica bibliográfica que permeiam esta temática, problemática e o Perfil Epidemiológico ao qual discute deste sua etimologia, seus objetivos e legalidade; no II - Epistemologia do Estudo da Parasitose no Brasil onde se aborda o seu surgimento as alterações sofridas no decorrer do tempo, bem como se dá o processo de parasitose no Brasil e sua classificação e por fim III - Discrição das Parasitoses Intestinais Humanas que trata das descrições gerais que vão desde a morfologia até o ciclo de reprodução e as principais parasitoses intestinais humanas e considerações finais.

Este se efetivara por meio do estudo bibliográfico descritivo narrativo de caráter qualitativo, com busca em duas bases de dados públicas Google Acadêmico e SciELO com três descritores: Perfil Epidemiológico; Parasitologia e Parasitose Intestinal Humana e Livros de autores renomados que discutem esta temática. 


\section{METODOLOGIA}

A respectiva pesquisa é de cunho bibliográfico, ao qual se caracteriza por seu desenvolvimento a partir de materiais científico já disponível (publicados), em sua maioria todos os trabalhos científicos se iniciam a partir desta natureza, no entanto esta pesquisa será desenvolvida excepcionalmente/exclusivamente neste contexto - revisão de literatura (GIL, 2008). O trabalho é de caráter qualitativo, pois nesta o que se importa não é apenas os resultados e sim todo o processo, visando compreender e descrever todos os aspectos complexos (LAKATOS, 2007).

Assim, foi realizado uma busca no Google acadêmico e SciELO por artigos completos publicados nos períodos de 2012 a 2018. Utilizando os seguintes descritores, Perfil Epidemiológico; Parasitologia e Parasitose Intestinal Humana. Para a seleção do material foi analisado, além dos dados acima se os contextos dos mesmos a pesquisa estão relacionados às Parasitoses Intestinais Humanas em no Brasil. Posteriormente foi computado para análise, atentando-se, ano de publicação, grupo estudado, tipo de parasitose.

\section{DISCUSSÃO TEÓRICA}

\section{Perfil Epidemiológico}

A epidemiologia teve origem a partir das observações da influência dos fatores do meio ambiente com as ocorrências das doenças por Hipócrates a cerca de 2000 anos, porem somente no século XIX que se começou a medir em larga escala a classificação das doenças por grupos específicos humanos (BONITA et al., 2010). $O$ termo Epidemiologia é de origem grega $E p i=$ Sobre + Demos $=$ População + Logos $=$ Estudos (PEREIRA, 2013; GOMES, 2015), tratando-se de um estudo a cerca de uma determinada população, especificadamente das moléstias que afetam uma coletividade.

No século XX, houve uma grande revolução na epidemiologia mediante os estudos do médico sanitarista Britânico John Snow como o desfecho da epidemia de cólera que ocorrera entre 1849-1854 em Londres, ficando conhecido como o "Pai da Epidemiologia", devido seu minucioso trabalho investigativo que detectou a origem da infecção desta doença mesmo desconhecendo seu agente etiológico (GOMES, 2015) da seguinte maneira:

John Snow identificou o local de moradia de cada pessoa que morreu por cólera em Londres entre 1848-49 e 1853-54 e notou uma evidente associação entre a origem da água utilizada para beber e as mortes ocorridas. A partir disso, Snow comparou o número de óbitos por cólera em áreas abastecidas por diferentes companhias e verificou que a taxa de mortes foi mais alta entre as pessoas que consumiam água fornecida pela companhia Southwark. Baseado nessa sua investigação, Snow construiu a teoria sobre a transmissão das doenças infecciosas em geral e sugeriu que a cólera era disseminada através da água contaminada. Dessa forma, foi capaz de propor melhorias no suprimento de água, mesmo antes da descoberta do micro-organismo causador da cólera; além disso, sua pesquisa teve impacto direto sobre as políticas públicas de saúde. O trabalho de Snow relembra que medidas de saúde pública, tais como melhorias no abastecimento de água e saneamento, têm trazido enormes contribuições para a saúde das populações. Ficou ainda demonstrado que, desde 1850 , estudos epidemiológicos têm identificado medidas apropriadas a serem adotadas em saúde pública. Entretanto, epidemias de cólera são ainda frequentes nas populações pobres, especialmente em países em desenvolvimento. Em 2006, houve em Angola 40 mil casos de cólera com 1.600 óbitos, enquanto no Sudão foram 13.852 casos e 516 mortes, somente nos primeiros meses do mesmo ano. (BONITA et al., 2010) 
Neste contexto, a epidemiologia está ligada ao estudo de saúde doença de uma particular população em dado tempo, apontando e classificando quais os fatores determinantes para acometimento e agravos de uma determinada doença, suas complicações e eventos relacionados à saúde coletiva. Permitindo assim, uma promoção de controle, prevenção e até erradicação de patologias. Além de fornecimento dos indicadores fidedignos que são fundamentais para o planejamento, gerenciamento e ações em saúde (ROUQUAYROL et al., 2013). Assim, o Quadro abaixo apresenta de forma sucinta a definição do termo e a relação com o processo saúde doença, baseando-se no estudo, distribuição, determinantes, estados ou eventos relacionados à saúde, população e aplicação na prevenção e controle.

Quadro 1: Definição da Epidemiologia.
\begin{tabular}{|l|l|}
\hline TERMO & EXPLICAÇÃo \\
\hline Estudo & Inclui vigilância, observação, teste hipótese e pesquisas analíticas e experimentais; \\
\hline Distribuição & Refere-se à analise quanto ao tempo, pessoas, lugares e grupos de indivíduos afetados; \\
\hline Determinantes & $\begin{array}{l}\text { Inclui fatores que afetam o estado saúde, dentre os quais, os fatores biológicos, químicos, sociais, } \\
\text { culturais, econômicos, genéticos e comportamentais. }\end{array}$ \\
\hline $\begin{array}{l}\text { Estados ou Eventos } \\
\text { relacionados à Saúde }\end{array}$ & $\begin{array}{l}\text { Referem-se a doença, causa de óbitos, hábitos comportamentais ( por exemplo: tabagismo), aspectos } \\
\text { positivos em saúde ( por exemplo: bem - estar, felicidade, etc.), reações a medidas preventivas, } \\
\text { utilização de serviços de saúde entre outros; }\end{array}$ \\
\hline População & Inclui indivíduos com características específicas como, por exemplo, crianças menores de cinco anos; \\
\hline $\begin{array}{l}\text { Aplicação na Prevenção } \\
\text { e Controle }\end{array}$ & O objetivo a saúde pública é promover, proteger e restaurar a saúde. \\
\hline
\end{tabular}

Fonte: Bonita et al. (2010).

A mesma agrega três técnicas das seguintes áreas do conhecimento segundo Gomes (2015) "estatística, ciências biológicas e ciências sociais" demostrando a amplitude do seu campo de atuação. Também, está compreende que os agravos patológicos são determinados por aspectos do ser/indivíduo, biológico e determinantes econômicos, social e cultural da comunidade que este vive e pelo estereótipo ambiental que o circunda, o que faz com que haja diferença no processo de saúde doença entre as populações (PEREIRA, 2013; GOMES, 2015). No que se refere aos objetivos desta Ciência a IAE (Associação Internacional de Epidemiologia) define três principais propostos pela Epidemiologia conforme o quadro abaixo:

Quadro 2: Objetivo da Epidemiologia.

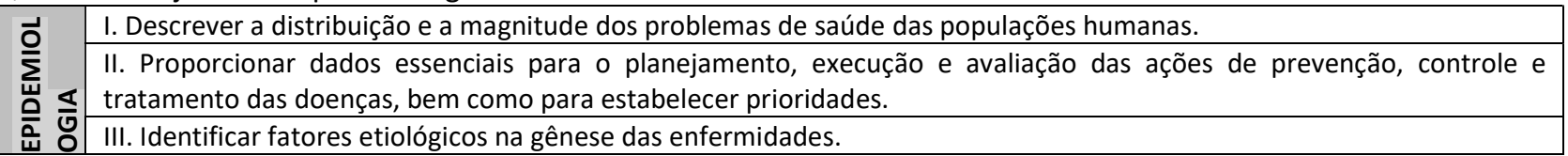

Fonte: Adaptado Brasil (2005).

Assim, os autores supracitados definem epidemiologia a partir destes três objetivos como um processo do conhecimento a partir da Ciência que tende a estudar o mecanismo de saúde doença de uma determinada população, a propagação, fatores essências da doença, os danos e eventos ocasionados à saúde coletiva, visando a partir de estes achados sugerir medidas de prevenção, controle, planejamento, administração, planejamento e avaliações das atividades em saúde (BRASIL, 2005). A criação do sistema da Vigilância Epidemiológica é regulamentada nacionalmente pela Lei Federal no. 6.259 de 30 de outubro de 1975, dos quais dispõem nos artigos:

Art. 8o - É dever de todo cidadão comunicar à autoridade sanitária local a ocorrência de 
fato, comprovada ou presumível, de caso de doença transmissível, sendo obrigatória a médicos e outros profissionais de saúde, no exercício da profissão, bem como aos responsáveis por organizações e estabelecimentos públicos e particulares de saúde e ensino, a notificação de casos suspeitos ou confirmados de doenças e agravos.

Art. 9o - É obrigatório proceder a investigação epidemiológica pertinente à elucidação do diagnóstico e tomar medidas de controle cabíveis, no caso das doenças do elenco de Doenças de Notificação Compulsória (DNC).

Art. 14 - A inobservância da presente lei constitui infração, sujeitando o infrator a penalidades previstas na Lei no 6437, de 20/8/1977, artigo 10, itens VI e VII. (BRASIL, 1975)

Posteriormente é promulgada a Lei orgânica de Saúde no. 8080/1990 retrata a legalidade no que dispõem o serviço de Saúde do país, ao qual aponta no Capitulo I, Art. 6 a Vigilância Epidemiológica como um campo de ação e atuação do Sistema Único de Saúde (SUS), conceituando a Vigilância Epidemiológica no § 2ㅇ como uma coleção de ações que tendem a proporcionar:

...conhecimento, a detecção ou prevenção de qualquer mudança nos fatores determinantes e condicionantes de saúde individual ou coletiva, com a finalidade de recomendar e adotar as medidas de prevenção e controle das doenças ou agravos. (BRASIL, 1990)

Com isso a epidemiologia além de estar amparada legalmente tem se tornado uma Ciência bastante ampla que aborda diversas áreas do saber, proporcionando diversas subdivisões como a explicitada por Pereira (2003) quando aponta que esta pode permear como epidemiologia clínica, nutricional, investigativa, de campo, descritiva.

Pereira (2003) aponta que esta pode ser apontada como três grandes áreas de atuação: I - descrição de situação e saúde coletiva mediante indicadores de saúde (taxa de incidência e mortalidade de uma determinada patologia). II - Averiguação de fatores que determinam a situação saúde (constatação de agentes etiológicos e possíveis fatores do processo doença e os riscos). III - Investigações e ponderamento das intervenções e impactos no quesito do saneamento básico com intuito de diminuir as parasitoses na comunidade.

Tais pressupostos são primordiais para a construção e compreensão do diagnóstico em saúde ao qual é retratado como uma ferramenta primordial para o planejamento e consequentemente a prestação de assistência de saúde efetiva, pois consiste em coleta de dados de saúde sistematizada de uma comunidade/população do qual tende de apurar informações relevantes que compõem condições demográficas, culturais, sociais e educacionais a fim da elaboração e composição do indicador de saúde. Assim, para realizar tal tarefa minuciosa, faz se necessário um profissional que domine tais conceitos e conheça as ferramentas disposta na epidemiológica que o auxilie em sua avaliação totalmente fidedigna para que não apresente erro na desenvoltura (ROUQUAYROL et al., 2013).

Esse viés aquisitivo pela epidemiologia proporciona o conhecimento da situação de saúde dos quais possui como objetivos subjacentes à elaboração de um plano de saúde que diminua os problemas encontrados através desse apontamento e proposições de hipóteses relacionadas aos fatores relacionados à construção e manutenção do cenário epidemiológico. Estas por sua vez deverão ser testadas. Logo o diagnóstico da situação de saúde de uma população é o primeiro passo a ser realizado para compreensão e possíveis secionamentos de problemas de saúde de qualquer população (GOMES, 2015). 


\section{Epistemologia do Estudo da Parasitose no Brasil}

Partindo do contexto histórico são notórias que as alterações epidemiológicas não seguem uma escala simples unidimensional, as doenças consideradas da pobreza têm sido substituídas pelas moléstias da atualidade, o que tem se observado é um grande conjunto de modificações, adaptações e mudanças necessárias peculiares para a sobrevivência dos seres vivos (MASCARINI, 2003; OLIVEIRA; 2013). No que ser refere ao estudo da parasitologia, esta tivera um marco predominante conforme relato do autor abaixo:

O estudo da parasitologia iniciou-se nos EUA em 1850 com Joseph Leidy, que ficou sozinho por aproximadamente 20 anos, publicando, entre outros trabalhos relevantes, a descrição, em 1860, do parasita Trichinella spirallis. Em 1910 foi fundada a Helmintological Society e em 1952 a American Society of Parasitology. (MASCARINI, 2003)

Dentre as patologias acarretadas pela "pobreza" são destacadas as enteroparasitárias ou parasitárias. O parasitismo é compreendido como um dentre as diversas cooptação entre dois organismos, sendo que não há um mecanismo unitário que possa identificar um ser/animal como parasita (WILSON, 2009). A parasitologia não foi marcada por uma sequência de grandes acontecimentos, ela se desenvolveu por volta dos séculos XIX a XX nos laboratórios das Universidades que em sua maioria não possuía estruturas e condições. Assim, seus progressos e achados em sua maioria foram realizados por homens solitários em diversas partes do mundo apoiado pelas Instituições (FOSTER, 2003; MASCARINI, 2003; OLIVEIRA, 2013).

A primeira escola de medicina tropical em clima temperado foi inaugurada em Liverpool em 1899, com Boyce como professor de patologia e chefe organizador, e Ross como conferencista convidado. Os maiores trabalhos da escola foram inicialmente testar as ideias de Ross na erradicação da malária através da destruição do vetor, e foi também nessa escola que Dutton identificou o primeiro tripanossomo humano, Trypanossoma gambiense, no sangue de um paciente e descrevendo logo após o segundo, o T. rhodesiense. (MASCARINI, 2003)

No que se refere no Brasil à parasitologia teve um segmento com a medicina Tropical, criando no século XIX a Sociedade de Medicina e Cirurgia no Rio de Janeiro que teve um papel fundamental no programa de adoção de medidas de higiene da população até a medicina legal, onde ouve desenvolvimento de mecanismos para melhoramento no atendimento de pessoas com deficiências mentais, alertas frente às condições e insalubridade das casas de prostituições frisando a inserção do saneamento básico (FOSTER, 2003).

Desta forma, diversos parasitologistas de prestigio da Escola Tropicalista na Baiana na época se organizavam juntamente com os médicos por volta de 1866 formando a denominada Gazeta Médica da Bahia na antiga capital do Brasil Colônia. É visto que o houvera divergência quanto à ideia do misticismo e a teoria dos germes pelos ambientalistas tropicalistas. Nesta época a escola de medicina brasileira estava mais interessada em provar que as investigações patológicas no país não eram cópia da Europa, impulsionando os estudos originais das patologias nativas da Bahia (BENCHIMOL, 2000).

Posteriormente implícita Oliveira (2013), corroborado por Nunes (2000) frente aos marcos que subsidiaram os demais avanços no Brasil no que se refere o combate das moléstias da época.

O instituto chefiado por Oswaldo Cruz foi a única instituição sul-americana a participar do 14을 Congresso Internacional de Higiene e Demografia, realizado em Berlim em 1907. Nesse evento, Oswaldo Cruz recebeu medalha de ouro pela sua atuação em Manguinhos, tendo 
essa condecoração uma enorme repercussão no Brasil. Em 1906 foi inaugurada, em Belo Horizonte, a primeira filial do antigo Instituto de Manguinhos e Carlos Chagas efetuou a primeira campanha antipalúdica, em Itatinga, interior de São Paulo, onde se construía uma hidrelétrica. Em 1908, o então denominado Instituto de Manguinhos foi renomeado de Instituto Oswaldo Cruz. O modelo de médico da época do campanhismo era Oswaldo Cruz, que sustentava que o saber se apoiava na pesquisa e na experimentação com o objetivo de combater as endemias e as epidemias ocorridas naquela época.

Assim, Pedro Severino e Júlio de Moura com as pesquisas embrionárias impulsionaram o programa de controle de parasitose no Brasil. Os estudos de Adolfo Lutz mostraram-se mais aguçado na implantação do mansoniano em campos ao qual não haviam sido explorados, assim como o da veterinária por helmintologistas brasileiros. Em 1841 a Escola Baiana supracitadas tinha como um dos membros José da Cruz Jobim mentor das pesquisas realizadas no Rio de Janeiro das doenças denominadas comumente como opilação, cansanção, caquexia Africana que acometiam os escravos (BENCHIMOL, 2000).

Segundo o Benchimol (2000) fora a partir dos estudos de Otto Wucherer, em 1985 e a realização da autópsia no corpo de um escravo que havia falecido diagnosticado de hipoemia - hipovolemia descobriu vermes da espécie Anchystomum duodenale (Verme intestinal) já descritas em 1838 por Angelo Dubini. Este pesquisador tivera uma morte prematura em 1873 por apoplexia cerebral (AVC- Acidente Vascular Cerebral), mesmo assim, continuará os estudos realizados na Escola da Bahia e Rio de Janeiro, porem somente sete anos mais tarde 1880, retomaram-se os estudos biológicos frente aos parasitas.

Assim, após 20 anos após o surgimento da escola na Bahia, fora criada a nova escola de Medicina por Oswaldo Cruz focada na saúde pública. Onde no governo do Presidente Rodrigues Alves assumiu o comando da área de saúde pública, recomendando ao congresso a transformação do Instituto Soroterápico Federal em um instituto que pesquisasse patologias infeciosas tropicais permeando a pesquisas de Pasteur em Paris. Tal, não fora concebido, porém empenhou-se destinado próprias verbas para aprimorar elevando a categoria do instituto Marquinhos provendo um alargamento de pesquisadores para estudo de doenças no sertão brasileiro especialmente a malária (BENCHIMOL, 2000).

Em São Paulo por volta do início do século XX quando se construía a Estrada de Ferro Noroeste com a derrubada da mata, iniciou-se epidemia de leishmaniose tegumentar ao qual se estendeu para a região noroeste do estado, Sorocaba e Alta Paulista. Fora a partir deste surto que houvera a denominação "úlcera de Bauru" devido ao acampamento dos trabalhadores se localizarem na cidade de Bauru. Pirajuí, Birigui, Penápolis, Araçatuba também foram alvo de surtos, acometendo os moradores das vilas e povoados, sitiantes, fazendeiros e operários incumbidos ao desmatamento (PESSÔA, 2007). Neste contexto:

Em outubro de 1910 Carlos Chagas apresenta à Academia Nacional de Medicina sua monografia sobre "Nova entidade mórbida do homem" (CHAGAS, 1910). Teodoro Bayma descreve os primeiros casos da doença, em São Paulo, em 1914, época em que é feito o primeiro levantamento entomológico no estado (COUTINHO, 1962). A única zona então infestada pelo Triatoma infestans era a região norte do estado, área de plantio de café e cana de açúcar (WANDERLEY, 1993). Assim como no caso da malária, a doença passará a ocupar as outras regiões do estado acompanhando a "onda verde" da expansão dos cafezais. Entre as endemias rurais importantes a última a aparecer em São Paulo foi a esquistossomose cujos primeiros casos autóctones foram registrados em Santos em 1923. (BARATA, 2000)

Assim, por meados do final do século $X X$, no estado do Rio de Janeiro a endemia retoma áreas 
periurbanas, devida o processo de desmatamento e loteamentos, onde o vetor apresentava variação. A área mais afetada se dera onde houve significativa transformação econômica como exemplo a mudança brusca da criação de gado pelo plantio de cana de açúcar ao qual contou com grande parte da mão de obra temporariamente de migrantes e consequentemente a redução da utilização de animais para realização das tarefas dos campos (BARATA 2000).

Com tais pressupostos Ferreira (2000) retrata que os patógenos mais comuns encontrados nos seres humanos se tratam dos parasitas intestinais. Tais se tratam de um grave problema de saúde pública, principalmente em países do terceiro mundo ao qual se dispõem de fatores cruciais contribuintes para o acometimento dos quis compromete o desenvolvimento mental e físico da população principalmente as de faixas etárias mais jovens apresentando quadro de diarreia crônica e até mesmo de desnutrição severa (LUDWIG et al., 2001).

\section{Discrição e Classificação das Parasitoses Intestinais Humanas}

Parasitoses intestinais são patologias que estão ligadas e correlacionadas às condições principalmente de saneamento básico e concebem um grande problema de saúde pública em países em desenvolvimento ou subdesenvolvido (OLIVEIRA, 2013). Estas possuem como agente etiológico os helmintos ou protozoários, em algum dos seus momentos do ciclo evolutivo de vida, localizando-se em alguma parte do intestino do hospedeiro, provocando diversas alterações que são patológicas (FEREIRA et al., 2004).

No que se refere à contaminação por Helmintoses, na população humana sua maior ocorrência está associada as: Ascaridiose, Tricuríase, Enterobiose, Ancilostomose e Estrongiloidíase, já nas protozooses ao qual acometem em sua maioria na infância a Giardíase e a Amebíase (SILVA et al., 2001; OLIVEIRA, 2013). Fernandes et al. (2012) membros da sociedade de infectologia Pediátrica publicou um artigo referindo -se: A sociedade de portuguesa pediatria consensos e recomendações onde apresentaram um quadro representando os principias parasitas intestinais.

\begin{tabular}{|lll}
\hline Protozoários & & \\
& Giardia lamblia & \multicolumn{1}{l}{ Entamoeba histolytica } \\
& Cryptosporidium parvum & Isospora belli \\
& Cyclospora cayetanensis & Blastocystis hominis \\
\hline Helmintas & & \\
\hline Nemátodes & Enterobius vermicularis \\
& Ascaris lumbricoides \\
& Trichuris trichiura \\
& Ancilostomas (Ancylostoma duodenale, \\
& Necator americanus) \\
& Strongyloides stercoralis \\
& Anisakis simplex \\
& Ténias (T. saginata, T. solium, \\
& Diphyllobotrium latum, Hymenolepsis nana) \\
Tremátodes & Schistosomas (S. intercalatum, S. mansoni, \\
& S. japonicum) \\
& Fasciolopsis buski, Heterophyes heterophyes, \\
& Euparyphium ilocanum, Metagonimus yokogawai \\
\hline
\end{tabular}

Figura 1: Principais Parasitas Intestinais. Fonte: Fernandes et al. (2012).

As infecções são ocasionadas pela ingestão de ovos, cistos ou pela penetração de larvas dos helmintos pela epiderme ou mucosa. As larvas, cistos e os ovos dos parasitos são despojados no meio 
ambiente juntamente com as fezes dos hospedeiros, e são dispersos pelos ventos, água ou o próprio hospedeiro que se contamina ou infecta os alimentos (SÀ-SILVA et al., 2010).

Desta forma o quadro 3 abaixo retrata de maneira simplificada a descrição clinica dos sinais e sintomas apresentados aos sujeitos contaminados de acordo com os principais patógenos intestinais. Seguindo a sequência disposta no quadro 1 supracitado:

Quadro 3: Apresentação Clínica frente às contaminações Intestinais.

\begin{tabular}{|c|c|}
\hline PATÓGENO & APRESENTAÇÃO CLÍNICA \\
\hline Giardia Iamblia & $\begin{array}{l}\text { Possui um amplo espectro clínico incluindo ausência de sintomas, diarreia aguda com ou sem vómitos e } \\
\text { diarreia crónica. A diarreia crónica associa-se frequentemente a sintomas de mal absorção intestinal (fezes } \\
\text { fétidas, flatulência, distensão abdominal), anorexia, má progressão ponderal ou perda de peso e anemia }\end{array}$ \\
\hline $\begin{array}{l}\text { Enterobius } \\
\text { vermicularis }\end{array}$ & $\begin{array}{l}\text { Predomina o prurido anal noturno, por vezes com agitação importante. São causa frequente de } \\
\text { vulvovaginite. A eventual relação causal com alguns sintomas como bruxismo, enurese noturna e perda de } \\
\text { peso nunca foi confirmada. }\end{array}$ \\
\hline $\begin{array}{l}\text { Ascaris } \\
\text { lumbricoides }\end{array}$ & $\begin{array}{l}\text { Pode cursar com queixas inespecíficas de dor ou desconforto abdominal e sintomas de mal absorção quando } \\
\text { a infecção é prolongada. Na fase de migração larvar pode haver envolvimento pulmonar, sob a forma de } \\
\text { pneumonite transitória aguda, com febre e eosinoflia (Síndrome de Löffler), que pode ocorrer semanas antes } \\
\text { da sintomatologia gastrointestinal. A obstrução intestinal alta é a complicação mais frequente em } \\
\text { parasitações volumosas. A migração dos vermes adultos através da parede intestinal pode provocar } \\
\text { colecistite, colangite, pancreatite de causa obstrutiva e peritonite. }\end{array}$ \\
\hline Trichuris trichiura & $\begin{array}{l}\text { Os indivíduos afetados podem manter-se assintomáticos, desenvolver um quadro disentérico (dor } \\
\text { abdominal, tenesmo, diarreia mucosanguinolenta) ou colite crónica, frequentemente com tenesmo e } \\
\text { prolapso rectal. Pode manifestar-se por anemia. }\end{array}$ \\
\hline $\begin{array}{l}\text { Entamoeba } \\
\text { histolytica }\end{array}$ & $\begin{array}{l}\text { A infecção pode variar de estado de portador assintomático (até } 90 \% \text { dos casos2) a doença invasiva grave. } \\
\text { A forma aguda pode cursar com diarreia sanguinolenta, associada a dor abdominal, tenesmo e desidratação. } \\
\text { Nesta fase podem surgir complicações graves incluindo mega cólon tóxico, colite necrosante fulminante e } \\
\text { perfuração intestinal. As formas crónicas manifestam-se por queixas intermitentes de dor abdominal e } \\
\text { diarreia não sanguinolenta, associadas a perda de peso. Pode ainda ocorrer ameboma ou abcesso hepático. }\end{array}$ \\
\hline Cryptosporidium & $\begin{array}{l}\text { Manifesta-se por diarreia aquosa profusa, por vezes com muco, sem sangue, com vómitos, náuseas, dor } \\
\text { abdominal tipo cólica e por vezes febre. A infecção pode ser assintomática, autolimitada ou arrastada. }\end{array}$ \\
\hline Ténias & $\begin{array}{l}\text { A infecção é frequentemente assintomática, mas pode cursar com sintomas gastrointestinais ligeiros } \\
\text { incluindo náuseas, diarreia e dor abdominal. A passagem das proglótides através do ânus, pode originar } \\
\text { desconforto e sensação de tenesmo. A infecção por Diphyllobotrium latum pode manifestar-se com } \\
\text { sintomas de anemia por carência de vitamina B12 como fadiga, palidez, glossite ou parestesias. }\end{array}$ \\
\hline Ancilostomas & $\begin{array}{l}\text { A infecção habitualmente ocorre pela penetração da larva através da pele, podendo posteriormente atingir } \\
\text { os pulmões, originando pneumonite normalmente ligeira. A infecção também pode ocorrer por ingestão, } \\
\text { sendo que a presença de vermes adultos no tubo digestivo se manifesta de forma inespecífica por dor } \\
\text { abdominal. A infecção intestinal pode levar à formação de úlceras com consequente perda crónica de } \\
\text { sangue e anemia microcítica hipocrómica moderada a grave. Pode também associar-se a hipoproteinémia e } \\
\text { edema. }\end{array}$ \\
\hline $\begin{array}{l}\text { Strongyloides } \\
\text { stercoralis }\end{array}$ & $\begin{array}{l}\text { A infecção ocorre por penetração da larva através da pele, atingindo posteriormente os pulmões. As queixas } \\
\text { intestinais assemelham-se à síndrome do cólon irritável, alternado períodos de diarreia com períodos de } \\
\text { obstipação, associados a dor abdominal intermitente. A infeç̧ão intestinal crónica cursa com diarreia } \\
\text { crónica, associada a sintomas de má-absorção. }\end{array}$ \\
\hline Anisakis simplex & $\begin{array}{l}\text { A infecção por este parasita, que ocorre através da ingestão de peixe cru ou malcozinhado, por originar um } \\
\text { quadro de gastrite com epigastralgias, náuseas e vómitos. Pode estar também na origem de reações } \\
\text { alérgicas (urticária aguda ou anaflaxia). }\end{array}$ \\
\hline Schistosomas & $\begin{array}{l}\text { A infecção ocorre por penetração das larvas através da pele. O envolvimento gastrointestinal manifesta-se } \\
\text { habitualmente por quadro de diarreia mucosanguinolenta, associada a dor abdominal intensa e } \\
\text { hepatomegália dolorosa. Pode associar-se a polipose cólica. A infecção por este parasita deve ser } \\
\text { considerada, em crianças que viajaram para áreas endémicas, que incluem a África subsaariana, América } \\
\text { Latina e Caribe. }\end{array}$ \\
\hline
\end{tabular}

Fonte: Adaptado de Fernandes et al. (2012).

Neves et al. (2005), segue conceituando e classificado os parasitos de acordo com a forma de contaminação/transmissão, o Quadro 4, abaixo retrata estas principais disposições bem como os conceitos estabelecidos. 
Quadro 4: Classificação dos Parasitos e Meios de Contaminação.

\begin{tabular}{|c|c|}
\hline PARASITO & FORMA DE TRANSMISSÃO \\
\hline S. Scabiei, P. púbis, P. humanus, T. vaginalis. & $\begin{array}{l}\text { Parasitos transmitidos entre pessoas devido ao contato } \\
\text { pessoal ou objetos de uso pessoal (fômites). }\end{array}$ \\
\hline $\begin{array}{l}\text { E. histolytica, G. lamblia, T. gondii, H. nana, cisticercose (ovos de T. } \\
\text { solium), A. lumbricoides, T. trichiura, E. vermicularis. }\end{array}$ & $\begin{array}{l}\text { Parasitos transmitidos pela água, alimentos, mãos sujas ou } \\
\text { poeira. }\end{array}$ \\
\hline $\begin{array}{llll}\begin{array}{l}\text { A. duodenale, } \\
\text { stercoralis. }\end{array} & N . & \text { americanus, } & S . \\
\end{array}$ & $\begin{array}{l}\text { Parasitos transmitidos por solos contaminados por larvas } \\
\text { (geo-helmintose). }\end{array}$ \\
\hline $\begin{array}{l}\text { Leishmania sp., T. cruzi, Plasmodium sp., S. mansoni, T.solium, 7: } \\
\text { saginata, K bancrojii, O. volvulus, M. ozzardi. }\end{array}$ & $\begin{array}{l}\text { Parasitos transmitidos por vetores ou hospedeiros } \\
\text { intermediários. }\end{array}$ \\
\hline T. penetram (bicho de pé) & $\begin{array}{l}\text { Parasitos transmitidos por mecanismos diversos: larvas de } \\
\text { moscas (miíases). }\end{array}$ \\
\hline
\end{tabular}

Fonte: Adaptado Neves et al. (2005).

Desta maneira, é perceptível que somente em situações inusitadas tais parasitas podem ser visualizados a olho nu. Logo se faz necessário o auxílio de amparos laboratoriais para diagnóstico e identificação do mesmo. Onde diferentes preparos de fezes são observados através de microscópios a fim de identificação de ovos, trofozoítos ou quistos. A presença destes está relacionada à fase do ciclo ao qual se encontra o parasita, podendo algumas vezes intermitentes fazendo necessário a repetição dos exames em diferentes períodos (FERNANDES et al., 2012).

\section{CONCLUSÕES}

É notório que a maioria das doenças parasitaria intestinal já são endêmicas no Brasil e estão espalhadas por diversas regiões do país. Como constatado no presente estudo estão relacionadas em maioria a questões de deficiência em saneamento básico, higiene até mesmo pessoal e em alguns casos falta de informação. Logo, somente a localidades com níveis socioeconômicas baixas, o que não é perceptível na pratica, pois há elevadas quantidades de pessoas acometidas por tais, em regiões - cidades com nível considerado satisfatório em saneamento básico e padrão socioeconômico.

Neste sentido, pode ser constada nesta pesquisa a ausência na quantidade de trabalhos de cunho científico que retratem essa temática disposta publicada nas duas bases de dados analisadas no final do ano de 2018 que retratem regiões do Brasil, no recorte temporal que fora desde o pronunciamento da Organização Mundial de Saúde referente à quantidade de pessoas acometidas por doenças oriundas dos parasitas intestinais no ano de 2000.

Assim, utilizando os descritores: Perfil Epidemiológico; Parasitologia e Parasitose Intestinal Humana, foram localizados 20 trabalhos completos no Google acadêmico e nenhum na sciELO. Nestes as prevalências dos estudos permeiam o acometimentos e estudos pelos parasitas Giardia lamblia e Endolimax nana. Além disso, percebe-se que as maiorias dos descritos são por pesquisadores biólogos e nenhum da área da enfermagem.

Logo, a relevância deste trabalho e a necessidade de apropriamos de tais conhecimentos/pesquisas tendo em vista que estes agravos são problemas de saúde pública que necessitaram em algum dado momento dos cuidados destes profissionais do qual deverá ter ciência dos sinais, sintomas assim como o processo de cuidado, conduta, agravos tal como a etimologia, ciclo e comportamento de tais parasitas. 


\section{REFERÊNCIAS}

BENCHIMOL, J. L.. A instituição da microbiologia e a história da saúde pública no Brasil. Ciência \& Saúde Coletiva, v.5, n.2, p.265-292, 2000. DOI: https://doi.org/10.1590/S1413$\underline{81232000000200005}$

BONITA, R.; BEAGLEHOLE, R.; KJELLSTRÖM, T..

Epidemiologia básica. 2 ed. São Paulo: Santos. 2010.

BRASIL. Lei n. 6.259 de 30 de outubro de 1975: dispõe sobre a organização das ações de vigilância epidemiológica, sobre o Programa Nacional de Imunizações, estabelece normas relativas a notificação compulsória de doenças, e das outras providências. Brasília: DOU, 1975.

BRASIL. Ministério da Saúde. Lei $\mathbf{n} . \mathbf{8 0 8 0}$ de 19 de setembro de 1990: dispõe sobre as condições para promoção, proteção e recuperação da saúde, a organização e o funcionamento dos serviços correspondentes e dá outras providências. Brasília: Ministério da Saúde, 1990. Brasília: DOU, 1990.

BRASIL. Curso Básico em Vigilância Epidemiológica (CBVE). Secretaria de Vigilância em Saúde. Brasília: Ministério da Saúde, 2005.

FERNANDES, S.; BEORLEGUI, M.; BRITO, M. J.; ROCHA, G.. Sociedade Portuguesa de Pediatria Consensos e Recomendações: Protocolo de parasitoses intestinais. Acta Pediatr, v.43, n.1, p.35-41, 2012.

FOSTER, W. D.. A history of parasitology. Londres: E \& S Livington Ltda., 1965.

GOMES, E. C. S.. Conceitos e ferramentas da epidemiologia. Recife: UFPE, 2015.

LUDWIG, K. M.; FREI, F.; ALVARES FILHO, F.; RIBEIRO-PAES, J. T.. Correlação entre condições de saneamento básico e parasitoses intestinais na população de Assis, estado de São Paulo. Revista da Sociedade Brasileira de Medicina Tropical, v.32, n.5, p.547-555, 2001.
MASCARINI, L. M.. Uma abordagem histórica da trajetória da parasitologia. Ciência \& Saúde Coletiva, v.8, n.3, p.809-814, 2003. DOI: http://dx.doi.org/10.1590/S0037$\underline{86821999000500013}$

NEVES, D. P.; MELO, A. L.; LINARDI, P. M.; VITOR, R. W. A.. Parasitologia humana. 11 ed. São Paulo: Atheneu, 2005.

OLIVEIRA, J. L.. Parasitoses Intestinais: O ensino como ferramenta principal na minimização destas patologias. Dissertação (Mestrado em Ensino Em Ciências da Saúde e do Meio Ambiente) - Centro Universitário de Volta Redonda, Volta redonda, 2013.

PEREIRA, M. G.. Epidemiologia: teoria e prática. Rio de Janeiro: Guanabara Koogan, 2013.

PESSÔA, S. B.. Problemas brasileiros de higiene rural. Rio de Janeiro: Guanabara Koogan, 2007.

ROUQUAYROL, M. Z.; GOLDBAUM, M.; SANTANA, E. W. P.. Epidemiologia, história natural e prevenção de doenças. In: ROUQUAYROL, M. Z.; GURGEL, M.. Epidemiologia \& saúde. 7 ed. Rio de Janeiro: Medbook, 2013. p.11-24.

SÁ-SILVA, J. R.; PORTO, M. J. F.; SOUSA, C. E. B.; ALMEIDA, F. V. P.. Escola, Educação em Saúde e Representações Sociais: problematizando as parasitoses intestinais. Pesquisa em Foco, v.18, n.1, p.82-95, 2010.

SILVA, C. G.; SANTOS, H. A.. Ocorrência de parasitoses intestinais da área de abrangência do Centro de Saúde Cícero Idelfonso da Regional Oeste da Prefeitura Municipal de Belo Horizonte, Minas Gerais. Revista de Biologia e Ciências da Terra, v.1, n.1, p.1-11, 2001.

WILSON, R. A.. Introdução à parasitologia. São Paulo: EPU, 2009.

A CBPC - Companhia Brasileira de Produção Científica (CNPJ: 11.221.422/0001-03) detém os direitos materiais desta publicação. Os direitos referem-se à publicação do trabalho em qualquer parte do mundo, incluindo os direitos às renovações, expansões e disseminações da contribuição, bem como outros direitos subsidiários. Todos os trabalhos publicados eletronicamente poderão posteriormente ser publicados em coletâneas impressas sob coordenação da Sustenere Publishing, da Companhia Brasileira de Produção Científica e seus parceiros autorizados. Os (as) autores (as) preservam os direitos autorais, mas não têm permissão para a publicação da contribuição em outro meio, impresso ou digital, em português ou em tradução. 